\title{
Modernisasi Administraasi Perpajakan dalam Rangka Optimalisasi Pelayanan Pajak Berbasis Digital
}

Redo Alpha Hernando ${ }^{1 *}$, Dian Wahyudin ${ }^{2}$

${ }_{1,2}^{2}$ Institut Ilmu Sosial dan Manajemen STIAMI, Jakarta, Indonesia

${ }^{1}$ alphahernando@gmail.com² zahidah181011@gmail.com

* corresponding author

\section{ARTICLE INFO}

\section{Keywords}

Modernization of Tax

Administration, Optimization

of Tax Service

\section{ABSTRACT}

In a tax policy, the measure of success lies in the tax administration itself. To provide optimal services to the community, tax reform is needed in the form of modernizing tax administration. The purpose of the modernization of tax administration is to increase tax compliance, increase public trust (trust), and increase the integrity of the tax apparatus. This study aims to provide an overview of how the modernization of tax administration can improve tax services and the ease that can be felt by taxpayers in complying with tax obligations and improve the integrity of tax officials in the management of the tax. The method used in this writing is descriptive qualitative, where the approach used is the study of literature. The results of this paper are an increase in state revenue from the tax sector, increased compliance and more optimal tax services by modernizing digital-based tax administration.

\section{PENDAHULUAN}

Pajak merupakan sumber penerimaan yang penting bagi negara yang berasal dari rakyat. Karena pajak merupakan sumber penerimaan negara yang utama, maka pemungutan pajak dapat dipaksakan berdasarkan undang-undang. Ada banyak hal yang mempengaruhi rendahnya penerimaan pajak di Indonesia ini. Yang pertama, rendahnya kemampuan pemerintah dalam mendata dan memungut pajak. Kedua, penyelewengan pajak yang dilakukan oleh oknum-oknum pemerintahan. Ketiga, rendahnya kesadaran warga negara akan memebayar pajak. Yang keempat, rendahnya kepercayaan warga negara terhadap pemerintahan dalam mengelola dan memanfaatkan pajak. Upaya yang dilakukan pemerintah dalam mengoptimalkan penerimaan negara dari sektor pajak salah satunya adalah dengan melakukan reformasi perpajakan, yaitu dengan melakukan reformasi terhadap Peraturan Perundang-undangan Perpajakan serta sistem administrasi perpajakan, agar basis pajak dapat semakin diperluas, sehingga potensi penerimaan pajak yang tersedia dapat dipungut secara optimal dengan menjunjung asas keadilan sosial dan memberikan pelayanan prima kepada wajib pajak.

Pada tahun 2015, Direktorat Jenderal Pajak menargetkan 50 juta wajib pajak. Namun, melihat kinerja dan kredibilitas aparat pemerintahan saat ini, target tersebut sulit dicapai. Pastinya semua masyarakat menginginkan tingginya pemasukan pajak di Indonesia. Sebab, dengan tingginya penerimaan pajak suatu negara, akan memudahkan negara dalam melakukan pembiayaan dan mencapai tujuan-tujuannya. Seperti tujuan yang diidamkan oleh seluruh warga negara Indonesia, yaitu masyarakat yang adil dan makmur. Namun, kesadaran akan membayar pajak bagi wajib pajak dan akuntabilitas pengelolaan pajak yang dilakukan oleh pemerintah harus ditingkatkan.

Untuk mewujudkan masyarakat yang adil dan makmur dengan mengoptimalkan penerimaan dari sektor perpajakan, pemerintah Indoneia sebenarnya telah melakukan reformasi dalam adminstrasi perpajakan dalam kurun waktu lebih dari 25 tahun, yang memberikan penyegaran bagi pelayanan perpajakan di Indonesia. Hal ini dilakukan untuk mewujudkan target pemerintah dalam mengoptimalkan penerimaan pajak di Indonesia serta memberikan kepastian hukum. Modernisasi perpajakan dilakukan agar sistem perpajakan dapat lebih efektif dan efisien, sejalan dengan perkembangan globalisasi yang menuntut daya saing tinggi dengan negara lain. Tax reform yang telah dilakukan meliputi kebijakan, administrasi dan peraturan. Modernisasi perpajakan dari sisi administrasi menjadi kunci keberhasilan yang siginifikan dalam pemungutan pajak..

Tujuan dilakukannya Tax reform pada suatu negara yaitu agar negara dapat menjalankan administrasi perpajakan yang efektif dan efisien (Rahayu, 2010).demi tercapainya target penerimaan pajak. Untuk itu perlu adanya peningkatan kualitas dan kuantitas sumber daya manusianya.. selain itu, diperlukan peningkatan 
kepatuhan wajib pajak akan kewajiban perpajakannya. Pengembangan teknologi juga menjadi salah satu faktor kunci kesuksesan dalam modernisasi administrasi perpajakan sebagai bentuk respon dari tantangan globalisasi.

Keberhasilan dalam implementasi kebijakan perpajakan didiukung dengan administrasi perpajakan yang baik. Untuk itu perlu dilakukan secara kontinyu perubahan-perubahan dalam administrasi perpajakan, agar pelayanan yang diberikan kepada masyarakat dalam maksimal. Dengan adanya Tax Reform diharapkan dapat meningkatkan compliance dari WP, meningkatkan trust dari masyarakat, serta membangun integrity dari petugas pajak. Selama ini target penerimaan pajak dan kepatuhan wajib pajak di Indonesia belum sesuai harapan pemerintah.

Hal ini dapat ditunjukkan dengan tax ratio Indonesia yang lebih rendah diantara negara-negara di Asia Tenggara misalnya Filipina, Malaysia dan Thailand. Capaian tax ratio Indonesia sekitar 12-13\% sedangkan Filipina 14\%, Malaysia 16\%, Thailand $17 \%$. Begitu juga jika dibandingkan dengan Korea Selatan 25\%, Afrika Selatan 27\%, dan Brasil 34\%, atau rata-rata negara berpenghasilan menengah-bawah (17 persen).

Berdasarkan fenomena yang dipaparkan di atas, penulis tertarik untuk meneliti bagaimana upaya yang telah dilakukan oleh pemerintah dalam modernisasi administrasi perpajakan dalam rangka optimalisasi pelayanan pajak, meningkatkan kepatuhan wajiba pajak dalam membayar pajak, meningkatkan kepercayaan masyarakat serta meningkatkan integritas aparat pajak. Penelitian ini bertujuan untuk memberikan gambaran bagaimana modernisasi administrasi perpajakan dapat meningkatkan pelayanan pajak dan serta kemudahan yang dapat dirasakan oleh wajib pajak dalam mematuhi kewajiban perpajakannya serta meningkatkan integritas aparat pajak dalam pengelolaan pajak tersebut. Metode yang digunakan dalam penulisan ini bersifat deskriptif kualitatif, dimana pendekatan yang digunakan adalah studi kepustakaan dengan sumber data dari jurnal, web, undang-undang, peraturan-peraturan dan buku-buku.

\section{PEMBAHASAN}

Salah satu fungsi pajak di Indonesia yaitu sebagai sumber APBN (Anggaran Pendapatan dan Belanja Negara). Sebagai salah institusi yang berada dalam naungan Kementerian Keuangan, DJP mengemban amanah untuk memberikan pelayanan kepada masyarakat dalam administrasi perpajakan. DJP memiliki target yang sangat besar yaitu menjadi model pelayanan masyarakat yang menyelenggarakan sistem dan manajemen perpajakan kelas dunia yang dipercaya dan dibanggakan masyarakat. Untuk mencapai target tersebut, DJP memiliki dengan meningkatkan penerimaan dalam negeri dari sektor pajak sebagai penopang pemerintah dalam membiayai keperluan negara dengan tingkat efektivitas dan efisiensi yang tinggi. Untuk mewujudkan target yang ditetapkan, DJP perlu melakukan Tax Reform dengan beralih ke sektor teknologi dan digitalisasi.

Dalam meningkatkan kinerja pelayanan perpajakan ada beberapa aspek yang harus diperhatikan dalam Tax Reform, seperti peningkatan kepatuhan wajib pajak dan membangun integritas petugas pajak. Kendala yang sering ditemui dalam administrasi pajak adalah wajib pajak merasa pelayanan yang diberikan sedikit menyulitkan dan membingungkan seperti mereka harus mengantri lama sehingga wajib pajak membutuhkan waktu lama dalam melakukan administrasi perpajakan

Sebagaimana diungkapkan oleh (Rosdiana \& Irianto, 2011, hal. 5) bahwa: Tax Reform dalam administrasi perpajakan harus dilakukan dengan pendekatan holistic dan menyeluruh". Pendapat lain dikemukan oleh (Rahayu, 2010, hal. 93) bahwa:

Administrasi perpajakan berperan penting dalam sistem perpajakan di suatu negara, suatu negara dapat dengan sukses mencapai sasaran yang diharapkan dalam menghasilkan penerimaan pajak yang optimal karena adminstrasi perpajakannya mampu dengan efektif melaksanakan sistem perpajakan di suatu negara yang dipilih".

Sehingga dapat disimpulkan bahwa administrasi perpajakan yang efektif dan efisien akan dapat meningkatkan kepatuhan dan penerimaan pajak secara optimal dalam suatu negara.

Reformasi administrasi perpajakan dapat dikatakan juga sebagai modernisasi administrasi perpajakan. (Pandiangan, 2007, hal. 7) mengemukakan pendapatnya bahwa sistem modernisasi administrasi perpajakan merupakan penyempurnaan proses bisnis dan restrukturisasi organisasi dengan memanfaatkan teknologi komunikasi dan informasi, serta penyempurnaan manajemen SDM yang menyesuaikan dengan iklim, kondisi dan sumber daya yang ada di Indonesia.

Adapun (Rahayu, 2010, hal. 110-115) menentukan indikator sistem modernisasi administrasi perpajakan adalah sebagai berikut:

1. Rekstrukturisai organisasi

2. Penyempurnaan proses bisnis melalui pemanfaatan teknologi komunikasi dan informasi

3. Penyempurnaan manajemen SDM

4. Pelaksanaan Good Governance 
Modernisasi administrasi perpajakan yang telah dilakukan oleh DJP dalam upaya mengoptimalkan pelayanan, kepatuhan wajib pajak dan integritas aparat pajak serta meningkatkan kepercayaan masyarakat diantarnya adalah dengan melakukan reformasi dalam sistem pelayananan yang berbasis digital, yaitu $e$ registration, e-faktur,e-billing, e-SPT,e-filling.

\section{E- Registration}

Dimulai pada tahun 2013 sistem pendaftaran wajib pajak untuk mendapatkan NPWP dilakukan secara online dengan memanfaatkan kemajuan teknologi informasi dan komunikasi, yang disebut dengan eregistration. Dengan e-registration, wajib pajak tidak perlu lagi datang ke KPP dimana ia berdomisili untuk mendaftarkan dirinya menjadi wajib pajak dan mendapatkan NPWP. Dari segi waktu menjadi lebih efisien bagi wajib pajak yang kegiatannya cukup padat. Dengan melakukan scan KTP asli dan mengisi formulir secara online, WP dinyatakan sudah terdaftar dan tinggal menunggu NPWP selesai dicetak. NPWP yang sudah jadi akan dikirim sesuai dengan alamat yang tertera di KTP. Hanya yang masih menjadi kendala adalah waktu dari pengiriman NPWP tersebut yang belum bisa dipastikan berapa lama akan sampai kepada WP.

Untuk menyempurnakan pendaftaran secara online maka Kementerian keuangan telah mengeluarkan Peraturan Menteri Keuangan Nomor 182/PMK.03/2015 tentang Tata Cara Pendaftaran NPWP, Pengukuhan PKP, Penghapusasn NPWP dan Pencabutan PKP. Di bawah ini merupakan alur pendaftaran secara online.

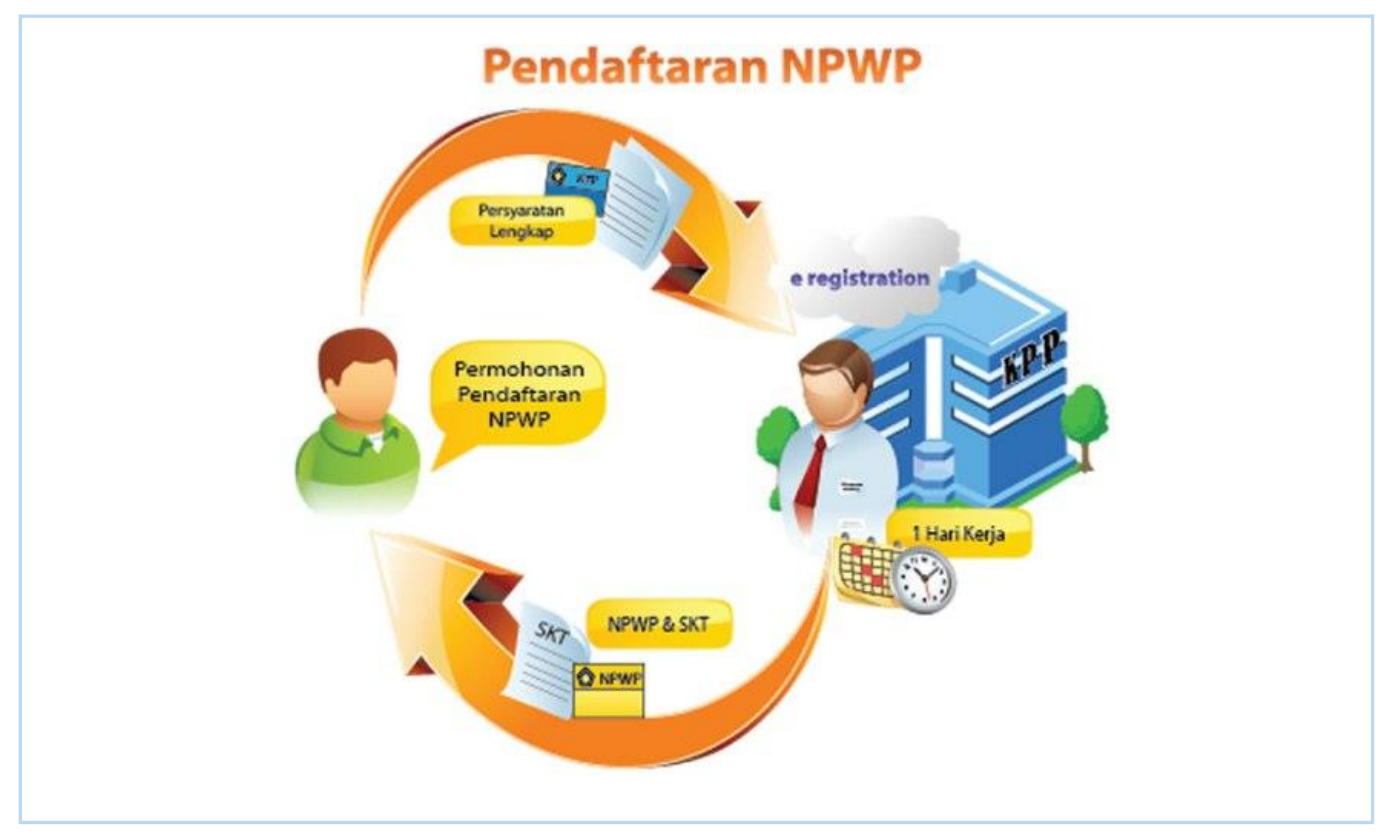

Sumber: www.pajak.go.id

Melalui e-Registration, pendaftaran wajib pajak untuk mendapatkan NPWP lebih efektif dan efisien dengan proses yang begitu mudah dan juga meringankan tugas DJP, dalam menyelesaikan permohonan pembuatan NPWP.

\section{Faktur Elektronik}

Sebagai bukti Pengusaha Kena Pajak (PKP) telah melakukan pungutan pajak atas penyerahan penyerahan Barang Kena Pajak (BKP) atau penyerahan Jasa Kena Pajak (JKP), PKP perlu membuat faktur pajak (Rosdiana \& Irianto, 2011). Sebagai bentuk modernisasi administrasi perpajakan untuk PPN, DJP telah membuat aplikasi atau sistem elektronik yang ditentukan dan/atau disediakan oleh Direktorat Jenderal Pajak yaitu faktur pajak elektronik atau e-faktur. Yang melatar belakangi dikeluarkannya aplikasi e-Faktur ini, karena banyak penyalahgunaan faktur pajak manual oleh Pengusaha Kena Pajak yang akhirnya merugikan negara. Seperti kasus faktur Pajak fiktif yang pernah terjadi dan mengakibatkan negara mengalami kerugian yang sangat besar untuk Pajak Pertambahan Nilai (PPN). Di bawah ini bagan mengenai manfaat e-faktur. 


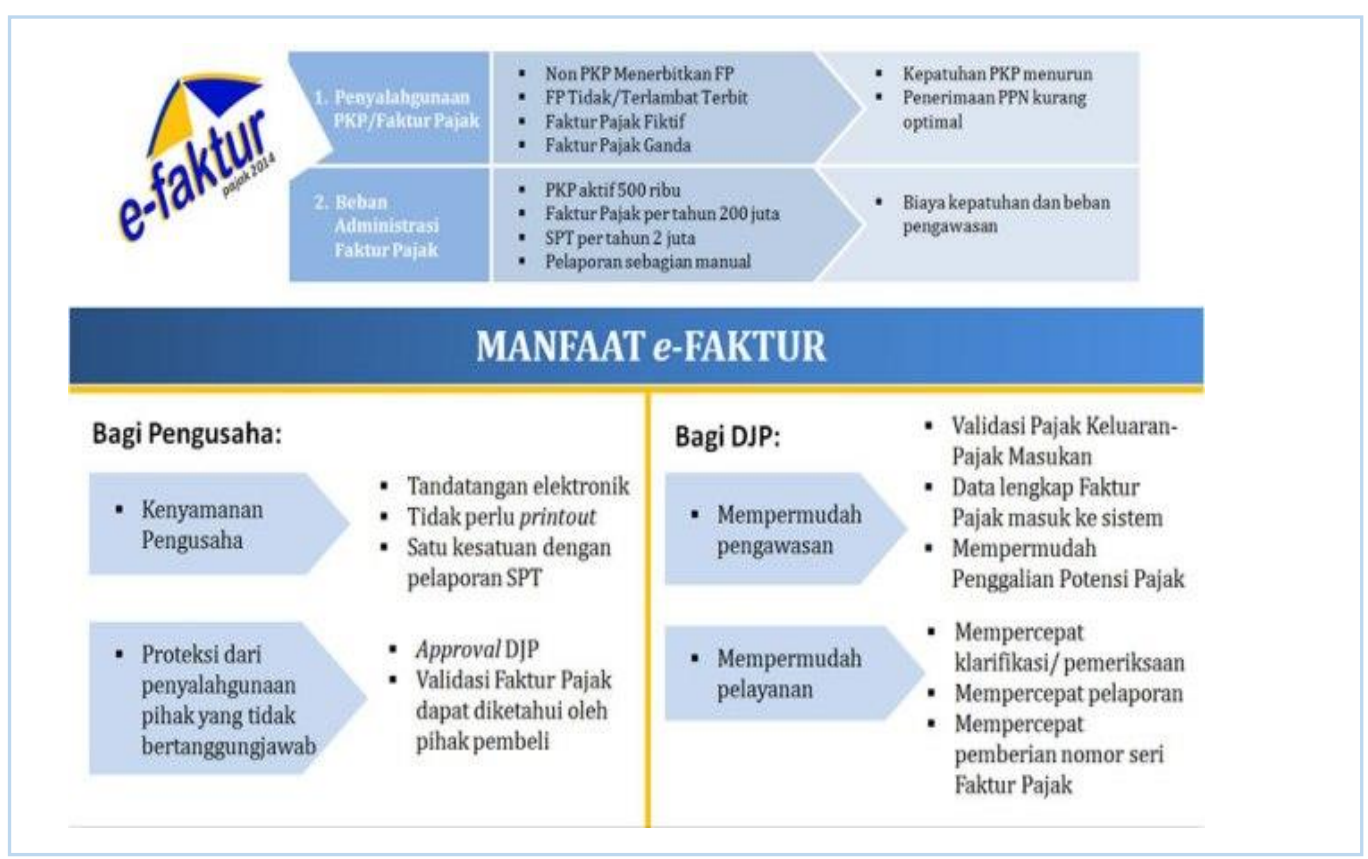

Sumber: www.pajak.go.id

Aplikasi faktur pajak elektronik yang dikembangkan oleh DJP bisa dijadikan sebagai pelaporan PPN secara online juga. Karena aplikasi ini antara $e$-Faktur e-SPT merupakan sistem yang terintegrasi. Dengan adanya sistem e-faktur, DJP menargetkan optimalisasi penerimaan PPN melalui peningkatan kepatuhan PPN. Di bawah ini grafik target penerimaan PPN sampai dengan tahun 2019

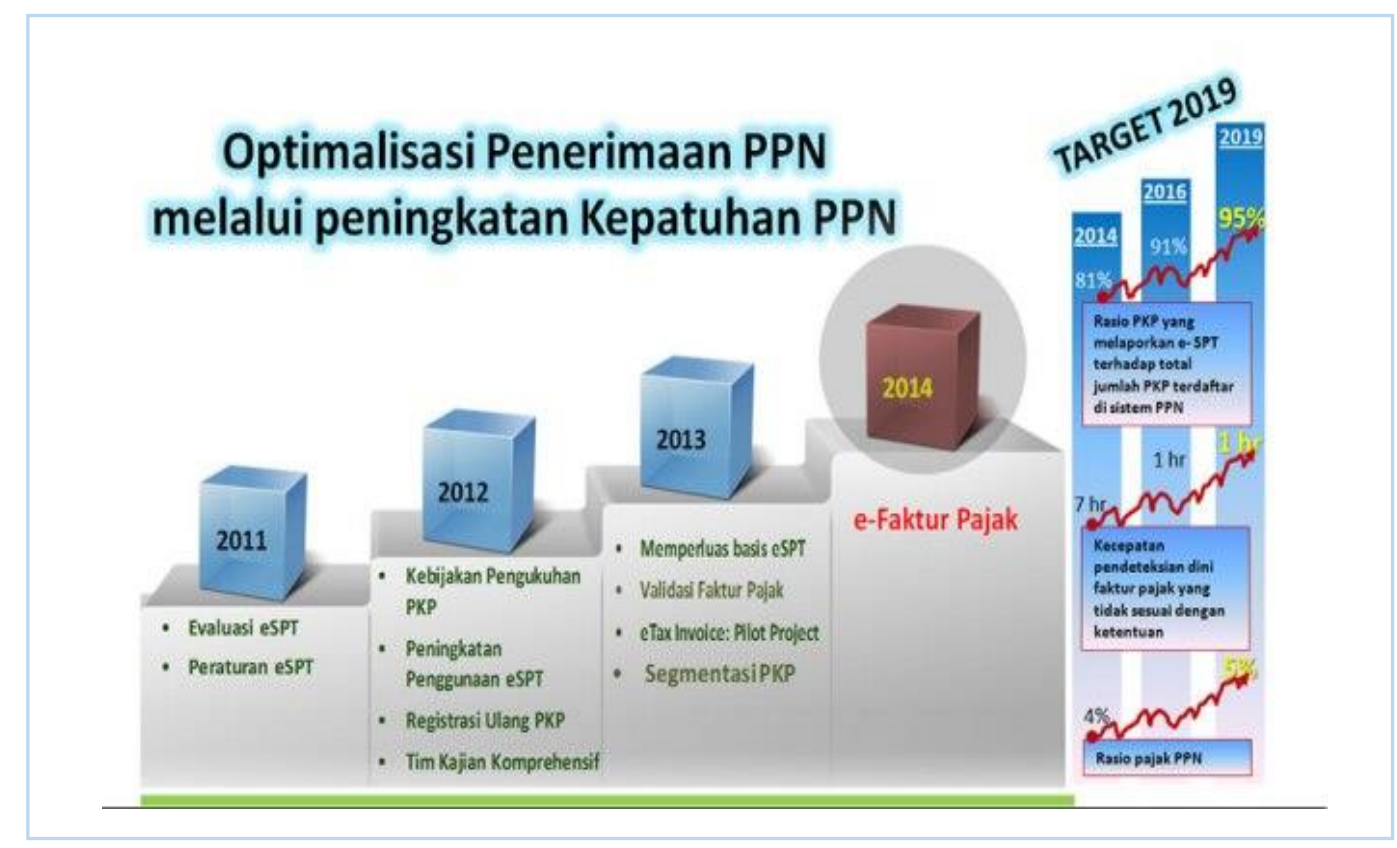

sumber:www.pajak.go.id

\section{SPT secara elektronik}

Dalam self assessment system, WP memiliki kewajiban untuk menghitung dan melaporkan pajak yang terutang sendiri. Dari hasil perhitungan akan di input dalam suatu formulir yang dikenal dengan Surat Pemberitahuan (SPT), ada SPT masa dan SPT tahunan. Sebelum adanya Tax Reform, penghitungan dan pengisian SPT dilakukan secara manual dengan mengandalkan sistem yang dibuat sendiri oleh WP.. Setelah SPT terinput, wajib pajak menyampaikan SPT tersebut ke Kantor Pelayanan Pajak dimana wajib pajak terdaftar.

Sistem pelaporan secara manual ini dirasakan tidak efektif dan efisien. Belum lagi jika data yang di input cukup banyak, tentunya membutuhkan waktu yang tidak sedikit. Dengan kondisi seperti itu, DJP telah 
mengembangkan sebuah aplikasi untuk pelaporan secara elektronik yang disebut dengan e-SPT. Tujuah dari e-SPT (elektronik surat pemberitahuan) untuk memberikan kemudahan kepada wajib pajak dalam membuat SPT paper less. Selain itu juga membuat tugas pegawai pajak menjadi lebih efektif dan efisien.

Dengan adanya aplikasi e-SPT ini, proses penghitungan tarif dan penjumlahan sudah dilakukan secara otomatis dan hasilnya akurat. Selain itu, data yang telah terinput dalam e-SPT sudah otomatis tersimpan dengan aman dalam database milik wajib pajak. Berbeda jika dilakukan secara manual, akan banyak berkas yang harus diserahkan ke KPP tempat WP terdaftar dalam fisik. Kondisi jelas tidak efektif dan efisien bagi WP. Begitu juga bagi petugas pajak yang harus melakukan perekaman data yang disampaikan agar bisa dilihat, diawasi, atau diteliti oleh sistem informasi di Direktorat Jenderal Pajak. Sedangkan berkas fisik SPT selanjutnya disimpan di dalam gudang.

Berbeda sekali apabila wajib pajak melapor pajak terutangnya dengan menggunakan SPT secara elektronik. Yang perlu dilaporkan oleh WP ke KPP hanya induk SPT saja bersamaan dengan file CSV yang dihasilkan dari aplikasi e-SPT. Setelah diterima oleh KPP, petugas langsung me-load file tersebut dan langsung masuk ke database DJP. Sehingga akan bisa di cek oleh sistem informasi di Direktorat Jenderal Pajak. Di bawah ini adalah alur penyimpanan data melalui e-spt:

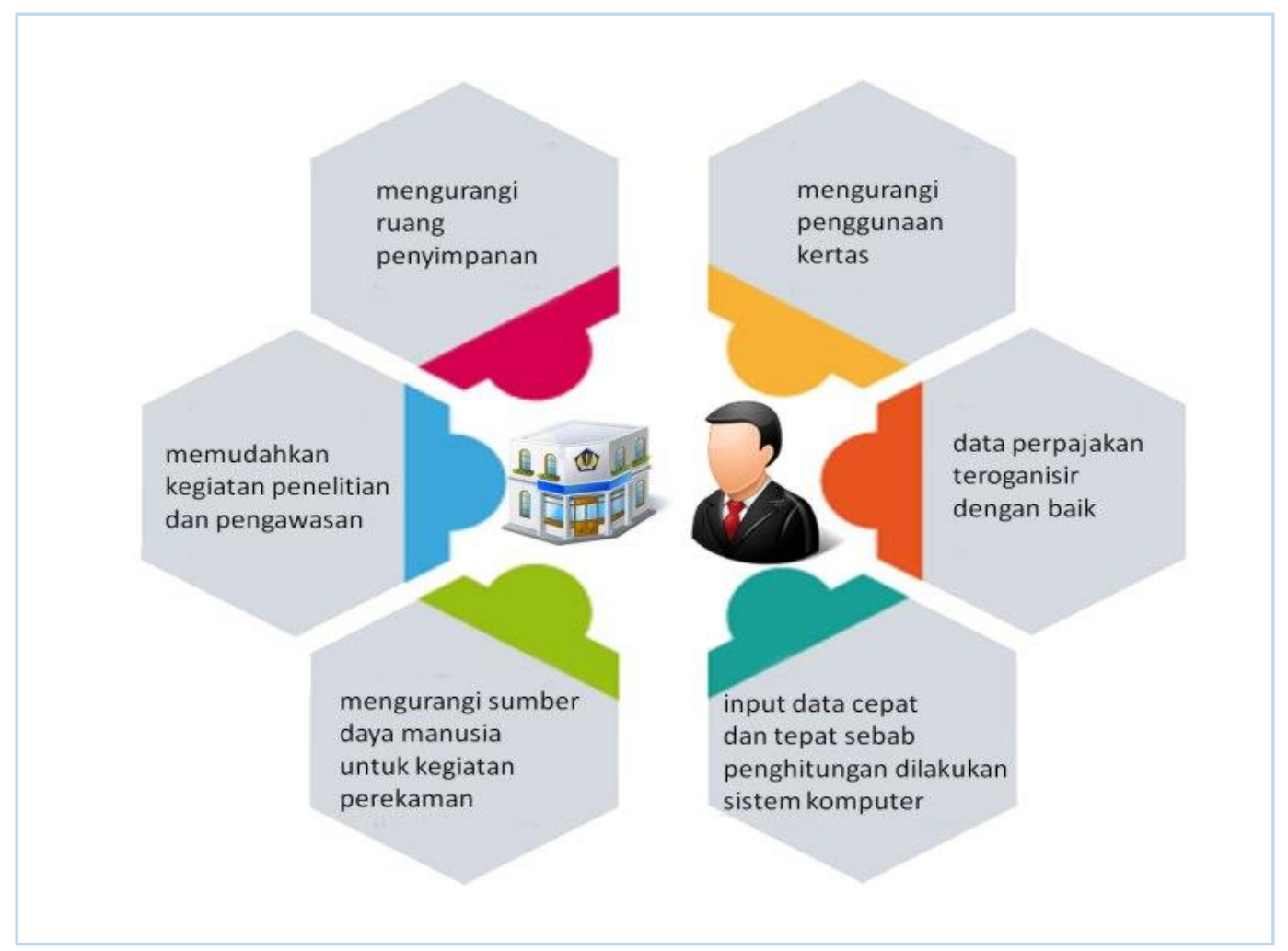

Sumber:www.pajak.go.id

\section{e-Filling}

Selain mengembangkan $e-S P T$, DJP juga telah melakukan modernisasi administrasi perpajakan dalam penyampaian SPT yang dilakukan secara online dan real-time melalui website Direktorat Jenderal Pajak atau Penyedia Jasa Aplikasi atau Application Service Provider (ASP). Penyampaian SPT dengan e-Filing, lebih efektif lagi, karena wajib pajak tidak perlu datang ke KPP untuk melaporkan SPT melainkan cukup mengakses website DJP atau ASP bisa dari rumah, kantor, atau warnet. Syarat untuk bisa menggunakan $e$-Filing, wajib pajak terlebih dahulu harus memiliki e-FIN (e-Filing Identification Number) dengan mengajukan permohonan ke KPP tempat WP terdaftar. Di bawah ini alur pelaporan melalui e-filling. 


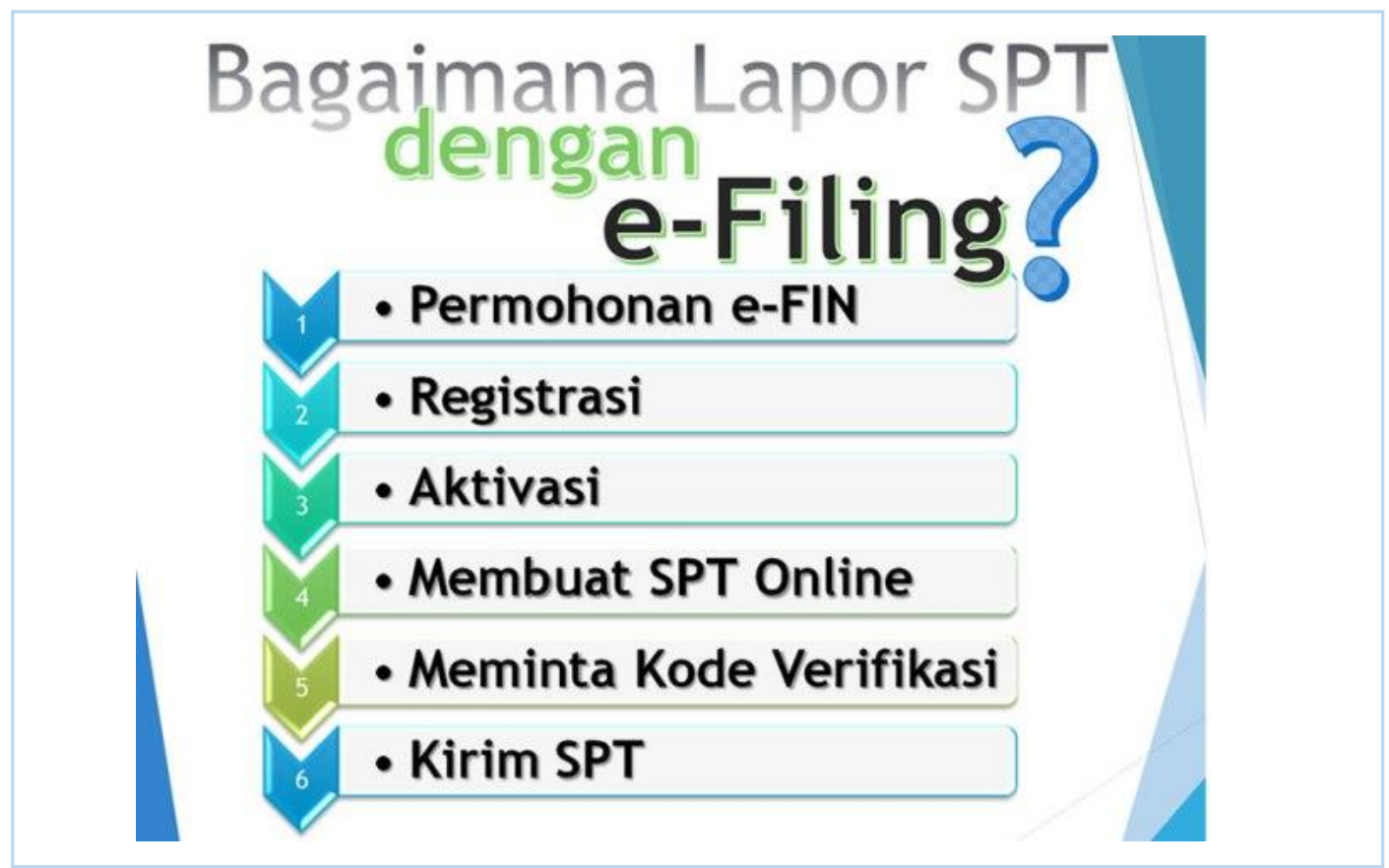

Sumber:www.pajak.go.id

Ada dua cara pelaporan SPT dengan e-Filing yaitu 1) WP cukup mengupload file CSV yang telah dihasilkan dari Aplikasi $e-S P T$. Ada beberapa jenis $e-S P T$ yang telah diakomodir di website DJP diantaranya SPT Tahunan OP (1770), SPT Tahunan OP Sederhana (1770 S), SPT Masa PPh Pasal 4 ayat (2), SPT Masa PPh Pasal 21/26, dan SPT Tahunan PPh Badan (1771). 2) Yaitu WP mengisi langsung SPT pada formulir yang telah disediakan di website DJP. Beberapa jenis SPT yang dapat menggunakan cara yang kedua diantaranya SPT Tahunan OP S (1770 S) dan SPT Tahunan OP SS (1770 SS). Di bawah ini target pelaporan SPT setelah menggunakan e-filling.

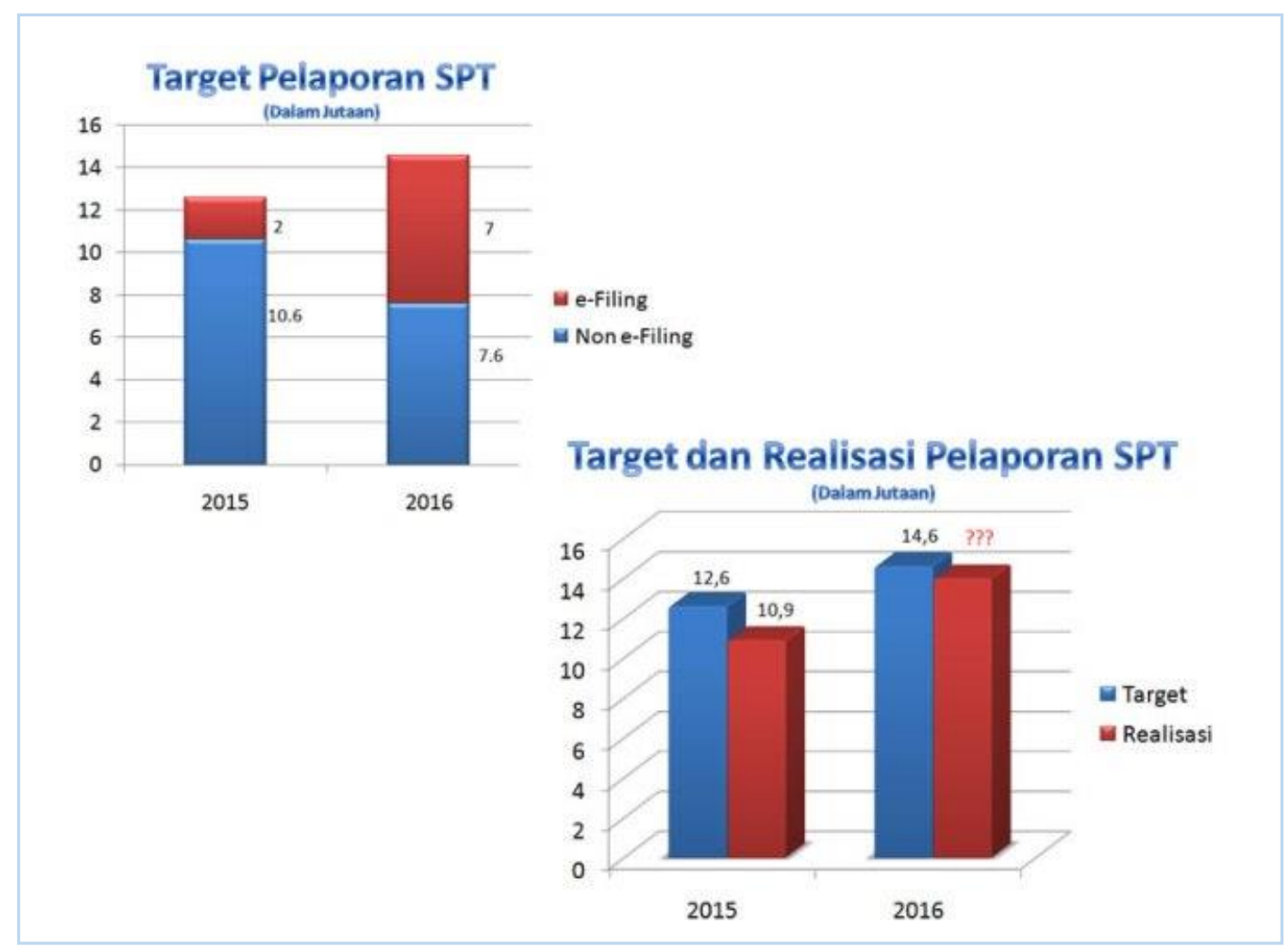

Sumber:www.pajak.go.id 


\section{Pembayaran secara elektronik.}

Kewajiban WP tidak hanya menghitung dan melaporkan pajak terutang saja, akan tetapi WP juga harus melakukan pembayaran atas pajak yang terutang baik melalui bank persepsi atau kantor pos dengan menggunakan formulir Surat Setoran Pajak (SSP). Namun sebelumnya WP harus mengisi formulir SSP secara manual.

Proses yang harus dijalani oleh WP ketika melakukan pembayaran secara manual di bank, yaitu menyerahkan SSP kepada teller. Lalu teller bank akan menginput kembali formulir SSP tersebut. Hal yang sering terjadi yaitu adanya kesalahan input baik yang dilakukan oleh WP ataupun teller bank. DJP telah melakukan modernisasi administrasi perpajakan dalam hal pembayaran dengan membuat aplikasi e-Billing untuk menghindari terjadinya kesalahan input. Ada kesamaan dalam aplikasi e-Billing dengan proses pembelian tiket pesawat secara online, seperti pengisian kota asal, kota tujuan, tanggal, dan jam keberangkatan.

Setelah pengisian secara, konsumen akan menerima kode pemesanan sebagai dasar pembayaran harga tiket. Begitu juga dengan e-Billing, WP terlebih dahulu mengisi pajak terutangnya, setelah itu WP akan menerima Kode Billing. Ketika sampai didepan teller bank, kantor pos, ATM, internet banking, atau mobile banking, WP cukup menyebutkan atau mengetik Kode Billing tersebut. Kondisi ini akan menghindari terjadi kesalahan input oleh teller bank. Dengan aplikasi, proses pembayaran pajak menjadi lebih efektif dan efisien serta lebih akurat..

\section{KESIMPULAN}

Dengan dilakukannya modernisasi administrasi perpajakan, DJP menargetkan penerimaan negara dari sektor pajak akan meningkat serta tax ratio di Indonesia pun akan meningkat pula. Selain penerimaan yang meningkat, diharapkan pula kemudahan dalam pelayanan kepada wajib pajak akan lebih prima sehingga akan berpengaruh pada kepatuhan wajib pajak dalam memenuhi kewajiban perpajakannnya. Kepercayaan kepada masyarakatpun diharapkan akan meningkatkan karena tingkat keamanan dari data yang telah diinput akan aman.

\section{DAFTAR PUSTAKA}

Pandiangan, L. (2007). Modernisasi dan Reformasi Pelayanan Perpajakan. Jakarta: PT Elek Media Komputindo.

Rahayu, S. K. (2010). Perpajakan Indonesia. Yogyakarta: Graha Ilmu.

Rosdiana, H., \& Irianto, E. S. (2011). Pengantar Ilmu Pajak. Jakarta: Raja Grafindo 